\title{
Rapid growth in early childhood associated with young adult overweight and obesity - evidence from a community based cohort study
}

Ratneswary Sutharsan ${ }^{1,2}$, Michael J. O'Callaghan ${ }^{3}$, Gail Williams ${ }^{1}$, Jake M. Najman ${ }^{1,4}$ and Abdullah A. Mamun ${ }^{1 *}$

\begin{abstract}
Background: Rapid weight gain in early life may increase the risk of overweight and obesity in adulthood. We investigated the association between the rate of growth during early childhood and the development of overweight and obesity in young adults.
\end{abstract}

Methods: We used a prospective cohort study of 2077 young adults who were born between 1981 and 1984 in Brisbane, Australia and had anthropometry measurements available at birth, 6 months, 5 years, 14 years and 21 years of age. The associations of rate of early growth with body mass index (BMI), waist circumference (WC) and waist-to-hip ratio (WHR) and their categories at 21 years were studied using multivariate analysis.

Results: We found that rapid weight gain [>+0.67 standard deviation score (SDS)] in the first 5 years of life was associated with young adults' overweight status (BMI: adjusted $\mathrm{OR}=2.35,95 \% \mathrm{Cl}, 1.82-3.03$; WC: adjusted $\mathrm{OR}=2.20$, $95 \% \mathrm{Cl}, 1.65-2.95)$. We also observed that slow weight gain in the first 5 years of age ( $<-0.67$ SDS) was inversely associated with overweight (BMI: OR=0.62, $95 \% \mathrm{Cl}, 0.45-0.84$ ). Such associations were not found with WHR. Rapid weight gain in the first 6 months of life increased the risk of overweight as defined by BMI (adjusted OR=1.13, $95 \% \mathrm{Cl}$, 0.86-1.49) and WC (adjusted OR=1.24, $95 \% \mathrm{Cl}, 0.92-1.67$ ), but these associations were not statistically significant.

Conclusion: Rapid weight gain in the first 5 years of life in children increased their risk of a higher BMI and WC in young adulthood, in contrast slow weight gain was inversely associated with weight status at 21 years.

\section{Background}

Globally, the prevalence of obesity has doubled during the last three decades, and in 2008 , more than $10 \%$ of the adult population was estimated to be obese [1]. There is insufficient evidence to consolidate prevention strategies targeted at adults or even to recognise the best age group for intervention. The potential risk of rapid postnatal weight gain on the development of obesity later in life has drawn considerable attention in the last decade. The association between rapid weight gain in infancy and obesity in later life has been reported in some observational studies [2-6], systematic reviews and meta-analyses [7-11]. A stronger association was found

\footnotetext{
* Correspondence: mamun@sph.uq.edu.au

${ }^{1}$ School of Population Health, The University of Queensland, Brisbane, Australia

Full list of author information is available at the end of the article
}

between postnatal weight gain and subsequent obesity in children compared to adults. Although some studies have tracked the longer term effects of early rapid weight gain $[3,4,12-15]$, potential mid-childhood mediating factors were hardly taken into account. Information on prospectively tracking the effects of both slow and rapid early growth into adulthood obesity status as measured by body mass index (BMI), waist circumference (WC) and waist-to-hip (WHR), in the contemporary population with a larger sample is limited. None of the studies have examined whether or not slow growth protects against obesity.

The aim of this study is to investigate the association between early weight gain in children and their overweight or obesity status in young adulthood with consideration to mid-childhood factors. We hypothesise that rapid weight gain in early life increases the risk of 
overweight, slow weight gain protects against overweight and mid-childhood factors, including food, physical activity and television-viewing mediate the associations.

\section{Methods}

The dataset used in this present study was collected from the Mater-University of Queensland of Pregnancy (MUSP), a prospective cohort study of 7223 women and their children who were born during the 1981-1984 period at the Mater Hospital in Brisbane, Australia. The Mater hospital is a tertiary hospital, located on the south side of the Brisbane River, which accommodated nearly $50 \%$ of the deliveries in Brisbane during 1981-1983 [16]. The mothers who participated in this study were public healthcare patients comprising $58 \%$ of the total mothers attending to the hospital. A detailed description of this cohort has been published previously [16, 17]. The mothers who gave birth to live singleton babies and did not give their babies for adoption constituted the MUSP birth cohort. The study has continued to measure factors indicative of the development, growth, health, learning and behaviour of offspring at critical stages of life: at the 6-month, 5-year, 14-year and 21-year followups [16]. The average age of the young adults at 21 years follow-up was 20.65 years, with a range from 18.17 to 23.53 years. Children who were born at $\geq 37$ weeks of gestation $\mathrm{N}=1993$ and consistently collected growth data at 6 month, 5 years, and 21 years were considered in this study.

Mothers consented to their participation and that of their babies. At 21 years, the young adults provided their consent to participate in the study. This study has been approved by the University of Queensland Ethics Committee and the Mater Hospital Ethics Committee.

In general, attrition rate was high in this long follow up study and individuals who were socially disadvantaged and had poor mental health were more likely to be lost of follow-up compared to respondents who remain in the study [16]. For this study, iformation was available for a sub-sample of 1993 offspring at birth, 5 years and 21 years. This attrition might have introduced some bias in the findings. However, distribution of important exposure and outcome variables included in the analyses did not vary considerably from the original cohort (Table 1).

\section{Measurements of outcome}

At the 21-year follow-up, the weight and height of the participants were measured during physical assessments. Two measures of height and weight were taken and the average value was used. Measurements were taken on a scale (Wedderburn Personal Scales Model UWBW150, Wedderburn, Japan) accurate to $0.2 \mathrm{~kg}$ when the participants were lightly clothed. Height was measured with a portable stadiometer (Road Rod 214 Portable Stadiometer, USA) and BMI was computed from height and weight measurements [weight/height $\left.{ }^{2}\left(\mathrm{~kg} / \mathrm{m}^{2}\right)\right]$. BMI was categorised into normal weight (BMI $\left.<25 \mathrm{~kg} / \mathrm{m}^{2}\right)$, overweight $\left(25-29.9 \mathrm{~kg} / \mathrm{m}^{2}\right)$ and obese $\left(\geq 30 \mathrm{~kg} / \mathrm{m}^{2}\right)$ [18] groups.

Hip circumference (HC) and WC were also measured at the physical assessments as described previously [19]. The participants' WHR was computed by dividing WC $(\mathrm{cm})$ by $\mathrm{HC}(\mathrm{cm}) . \mathrm{WC}$ was categorised into three groups $[18,19]$ : normal (females $<80 \mathrm{~cm}$; males $<94 \mathrm{~cm}$ ); overweight (females $80-<88 \mathrm{~cm}$; males $94-102 \mathrm{~cm}$ ); and obese (females $\geq 88 \mathrm{~cm}$; males $\geq 102 \mathrm{~cm}$ ). WHRs were also categorised into three groups [18]: normal (females $<0.8$; males $<0.9$ ); overweight (females $>0.8-<0.85$; males $>$ $0.9-<1.0$ ) and obese (females $\geq 0.85$; males $\geq 1.0$ ).

\section{Measurement of exposures}

Postnatal weight gain: Birth weight was measured at the hospital and each child's weight at 6 months was obtained by administrating 6-month follow-up questionnaires to the mothers. The children's weight at birth and at 6 months was measured in grams. Information was obtained from mothers who were 4-9 months postdelivery (mean 6.07 months) and age and sex adjusted zscores for weight were internally calculated. The z-score of the postnatal weight gain was computed by subtracting the $\mathrm{z}$-score weight at birth from the $\mathrm{z}$-score weight at the 6 -month follow-up. The values of weight $<-4$ SDS and $>+5.0$ SDS were omitted in the analyses [8]. As previously considered by Ong et al. [2] the z-score of postnatal weight gain was categorised into slow $(<-0.67 \mathrm{SDS})$, gradual $(\geq-0.67$ to $\leq+0.67$ SDS $)$ and rapid growth $(>+$ 0.67SDS).

Early childhood weight gain: At the 5-year follow-up, the weight of the participants was measured during their physical assessments. Measurements were taken on a scale accurate to $0.2 \mathrm{~kg}$ when the participants were lightly clothed. Two measures of weight were taken and the average value was used. The age- and sex-adjusted zscore values for weight at 5 years were computed. As shown previously, a z-score of weight gain greater than 0.67SDS was considered rapid growth from 0 to 5 years in children.

\section{Measurements of confounders and mediators}

Potential confounding factors considered in the study include: gestation age (in weeks), parity, gender, maternal education, maternal pre-pregnancy BMI, parents' racial background and maternal smoking. Maternal BMI $\left(\mathrm{kg} / \mathrm{m}^{2}\right)$ was computed from self-reported pre-pregnancy weight and height which were obtained during the first visit to the clinic (FVC). Weight measurements obtained at the first visit to clinic were highly correlated with self-reported maternal pre-pregnancy weight $(r=0.950)$. The socioeconomic status of the mothers was measured through 
Table 1 Comparison of mean values and the frequencies of crucial child and maternal characteristics from the main analysis group with the original MUSP cohort

\begin{tabular}{|c|c|c|c|c|c|c|}
\hline \multirow{2}{*}{ Parameter } & & \multicolumn{2}{|c|}{ Original cohort } & \multicolumn{2}{|c|}{ Main analysis set } & \multirow[b]{2}{*}{$P$ value $^{*}$} \\
\hline & & $\bar{N}$ & $\%$ or Mean (SD) & $\bar{N}$ & $\%$ or Mean (SD) & \\
\hline \multirow[t]{2}{*}{ Gender } & Male & 3579 & 51.7 & 1025 & 49.4 & 0.06 \\
\hline & Female & 3348 & 48.3 & 1052 & 50.6 & \\
\hline Gestation (weeks) & & 6927 & $39.6(1.27)$ & 2077 & $39.6(1.28)$ & 1 \\
\hline Birth weight (g) & & 6926 & $3430(469)$ & 2077 & $3438(462)$ & 0.5 \\
\hline Z-score of birth weight & & 6925 & $0.05(0.98)$ & 2077 & $0.08(0.96)$ & 0.2 \\
\hline Z-score of weight at 6 months & & 5451 & $-0.19(1.44)$ & 2077 & $-0.17(1.2)$ & 0.6 \\
\hline Z-score of weight gain $0-6$ months & & 5450 & $-0.25(1.50)$ & 2077 & $-0.25(1.27)$ & 1 \\
\hline Absolute weight at 5 years $(\mathrm{kg})$ & & 3827 & $20.5(3.1)$ & 1910 & $20.5(3.0)$ & 1 \\
\hline Z-score weight at 5 years & & 3927 & $0.25(1.01)$ & 1910 & $0.28(0.99)$ & 0.7 \\
\hline Z-score of early childhood weight gain $0-5$ years & & 3826 & $0.16(1.19)$ & 1910 & $0.14(1.17)$ & 1 \\
\hline Height at 21 years $(\mathrm{cm})$ & & 2550 & $171.7(9.2)$ & 2077 & $172(9.3)$ & 0.3 \\
\hline Weight at 21 years $(\mathrm{kg})$ & & 2522 & $71.7(16.2)$ & 2077 & $71.7(16.2)$ & 1 \\
\hline BMl at 21 years $\left(\mathrm{kg} / \mathrm{m}^{2}\right)$ & & 2522 & $24.2(4.96)$ & 2077 & $24.2(4.9)$ & 1 \\
\hline Waist circumference $(\mathrm{cm})$ & & 2523 & $81.7(12.4)$ & 2074 & $81.7(12.3)$ & 1 \\
\hline Waist to hip ratio & & 2520 & $0.83(0.08)$ & 2072 & $0.83(0.08)$ & 1 \\
\hline \multirow[t]{3}{*}{ Breast feeding } & Yes $\geq 4$ months & 1911 & 29.9 & 731 & 35.3 & $<0.001$ \\
\hline & Yes $<4$ months & 3142 & 49.1 & 1000 & 48.2 & \\
\hline & Not at all & 1344 & 21 & 342 & 16.5 & \\
\hline \multirow[t]{4}{*}{ Parity-previous births } & No birth & 2804 & 40.5 & 863 & 41.6 & 0.1 \\
\hline & 1 & 2128 & 30.7 & 650 & 31.3 & \\
\hline & 2 & 1186 & 17.1 & 361 & 17.4 & \\
\hline & $\geq 3$ & 809 & 11.7 & 203 & 9.8 & \\
\hline \multirow[t]{3}{*}{ Mother's education-FVC } & Incomplete high & 1240 & 18.1 & 318 & 15.4 & $<0.001$ \\
\hline & Complete high & 4422 & 64.3 & 1322 & 64.1 & \\
\hline & Post high & 1213 & 17.6 & 424 & 20.5 & \\
\hline \multirow[t]{3}{*}{ Parents' racial background } & Caucasian & 6008 & 89.4 & 1885 & 93.3 & $<0.001$ \\
\hline & Asian & 290 & 4.3 & 68 & 3.4 & \\
\hline & Abor-Islander & 424 & 6.3 & 68 & 3.4 & \\
\hline \multirow[t]{3}{*}{ Maternal smoking-FVC } & None & 4271 & 62.2 & 1373 & 66.6 & 0.001 \\
\hline & Smoker & 2010 & 29.3 & 545 & 26.4 & \\
\hline & Heavy & 581 & 8.5 & 143 & 6.9 & \\
\hline Mother's age at birth (years) & & 6927 & $25.5(5.10)$ & 2077 & $26.0(5.0)$ & $<0.001$ \\
\hline Mother's Pre-pregnancy BMI $\left(\mathrm{kg} / \mathrm{m}^{2}\right)$ & & 6395 & $21.9(3.90)$ & 1958 & $21.9(3.7)$ & 0.8 \\
\hline
\end{tabular}

$B M I$ body mass index, FVC first visit to clinic

${ }^{*} P$-value indicates the level of significance; for categorical outcome, $X 2$ test was applied; for continuous outcome, $\mathrm{F}$ test was used. Level of significance was set $<0.05$

a recommended proxy measure: maternal education, which was collected during the FVC of the study. Maternal smoking at FVC was also considered as confounding factors.

Breastfeeding reported at 6-month follow-up (never, $<4$ months 4 or more months) was considered a mediator. Adolescent's pubertal development was considered a mediator. The development of puberty at 14 years was obtained through self-revealed information using Tanner drawings (Stages 1-5) [20, 21]. For statistical precision, these stages were further grouped into three categories: Stages 1 and 2; Stage 3; and Stages 4 and 5. Information on fast food consumption was obtained from selfadministered questionnaires. Children's physical activity was also measured from the self-administrated questionnaire in which they were asked about their engagement 
in exercise or sports in the previous week. The number of hours a child watched television on a weekday was obtained from their mothers' reports.

\section{Statistical analysis}

To determine any significant difference between the characteristics of the original cohort and the subsample included in the main analysis, $X^{2}$ tests were performed for categorical variables (or for frequencies) and F-tests for continuously distributed variables. Multivariate logistic regression analyses were performed separately for each outcome variable after adjusting for potential confounders: gender, gestation, breast-feeding, parity, stages of puberty, fast food consumption at 14 years, television-viewing at 14 years, physical activity at 14 years, maternal education, maternal age at birth, maternal pre-pregnancy BMI, maternal smoking and race. As the exclusion of puberty did not influence the effect size, it was not included in the final model. In order to increase the statistical precision, the overweight and obese categories of the outcome variables were grouped together and considered as the overweight category.

The significant level was set as $P<0.05$ (two-tailed). All the analyses were carried out using Stata IC Version 12.1 software (STATA Corp. Texas, USA).

\section{Results}

The predictor and outcome measurements did not significantly differ between the original cohort and analytic sample (Table 1). Childhood factors in the main analysis set-physical activity, television-viewing and fast food consumption by family-did not differ significantly from those in the original cohort (results not shown). However, the children in the main analysis set were more likely to be breast fed $(P=0.001)$ than those in the original cohort. Compared to the original MUSP cohort, a significantly higher percentage of mothers with higher education and a Caucasian background and who were non-smokers (pre-pregnancy) were found in the main analysis set $(P=0.001)$.

Nearly $22 \%$ of infants showed rapid weight gain in their first six months of life. Male children showed a higher growth rate than female children $(24.3 \%$ and $19.1 \%$, respectively) (Fig. 1). Children who were first born, and bottle-fed and had less educated, smoking and younger mothers were more likely to grow rapidly in their first six months of life (results not shown). In the first five years of life, $32 \%$ of children exhibited rapid growth whereas $23.1 \%$ of children grew below 0.67SDS (Fig. 1). The rate of weight gain during the first five years of life was significantly associated with maternal education, smoking and parity $(P<0.001)$ (results not shown). When comparisons of important perinatal characteristics by rate of weight gain (slow, gradual and rapid) were made, it was found that rapid growers had a significantly higher gestation period and lower birth weight compared to children who exhibited gradual or slow growth.

Children who exhibited rapid weight gain had higher physical measurements at 21 years compared to gradual growers. Both males and females exhibited similar patterns. However, a significant difference was found between weight, BMI and WC measurements $(P<0.001)$ (Table 2).

Based on their BMI measurements, the prevalence of overweight was $33.6 \%$ among young adults, which was comparable to the national prevalence for this age interval during this period [22] and it did not significantly differ between the male and female groups $(P=0.7)$ (results not shown). When obesity status was classified by WC measurements, more females were overweight compared to males and the overall prevalence of overweight was in line with the classification of overweight by BMI. Based on WHR measurements, nearly $21 \%$ of young adults were overweight and the prevalence was higher

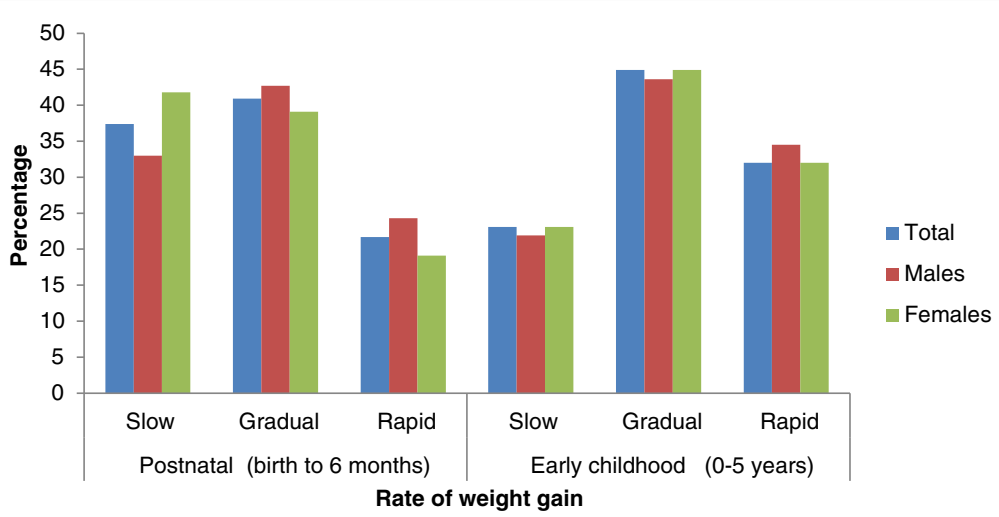

Fig. 1 Rate of postnatal and early childhood weight gain (\%) during postnatal and early childhood period in the MUSP cohort. [Slow: $<-0.67$ SDS; Gradual: $\geq-0.67-\leq+0.67$; Rapid: > + 0.67 SDS] 
Table 2 Distribution of outcome variables by the rate of early childhood weight gain ( $0-5$ years) categories

\begin{tabular}{|c|c|c|c|c|c|c|c|c|c|c|c|c|c|c|c|c|c|c|c|c|}
\hline \multirow[t]{4}{*}{ Parameter } & \multicolumn{20}{|c|}{ Rate of growth ( $0-5$ years) by gender } \\
\hline & \multicolumn{10}{|c|}{ Males } & \multicolumn{10}{|c|}{ Females } \\
\hline & \multicolumn{3}{|c|}{ Slow $(<0-0.67)$} & \multicolumn{3}{|c|}{$\begin{array}{l}\text { Gradual } \\
(\geq-0.67-\leq+0.67)\end{array}$} & \multicolumn{3}{|c|}{ Rapid $(>+0.67)$} & \multirow{2}{*}{$\begin{array}{l}\text { Gradual vs rapid } \\
P \text { value* }\end{array}$} & \multicolumn{3}{|c|}{ Slow $(<0-0.67)$} & \multicolumn{3}{|c|}{$\begin{array}{l}\text { Gradual } \\
(\geq-0.67-\leq+0.67)\end{array}$} & \multicolumn{3}{|c|}{ Rapid (> + 0.67) } & \multirow{2}{*}{$\begin{array}{l}\text { Gradual vs rapid } \\
P \text { value }^{*}\end{array}$} \\
\hline & $\mathrm{N}$ & Mean & SD & $\mathrm{N}$ & Mean & SD & $\mathrm{N}$ & Mean & SD & & $\mathrm{N}$ & Mean & SD & $\mathrm{N}$ & Mean & SD & $\mathrm{N}$ & Mean & SD & \\
\hline Height at 21 years $(\mathrm{cm})$ & 206 & 176.3 & 7.02 & 411 & 178.8 & 6.5 & 325 & 179.7 & 6.71 & 0.07 & 236 & 164 & 6.4 & 446 & 165.2 & 5.91 & 286 & 166.6 & 6.05 & 0.002 \\
\hline Weight at 21 years (kg) & 206 & 72.0 & 13.6 & 411 & 75.7 & 14.32 & 325 & 83.3 & 15.5 & $<0.001$ & 236 & 60.3 & 12.5 & 446 & 65.6 & 14.0 & 286 & 72.8 & 17.5 & $<0.001$ \\
\hline BMl at 21 years $\left(\mathrm{kg} / \mathrm{m}^{2}\right)$ & 206 & 23.1 & 4.17 & 411 & 23.7 & 4.0 & 325 & 25.8 & 4.61 & $<0.001$ & 236 & 22.4 & 4.38 & 446 & 24.0 & 5.06 & 286 & 26.2 & 6.13 & $<0.001$ \\
\hline Waist circumference at 21 years $(\mathrm{cm})$ & 206 & 82.4 & 10.04 & 411 & 84.4 & 10.3 & 325 & 88.8 & 12.04 & $<0.001$ & 235 & 74.7 & 10.35 & 445 & 77.7 & 11.5 & 285 & 82.3 & 13.75 & $<0.001$ \\
\hline Waist to hip ratio (WHR) at 21 years & 206 & 0.86 & 0.06 & 411 & 0.87 & 0.06 & 323 & 0.87 & 0.06 & 1.0 & 235 & 0.79 & 0.07 & 445 & 0.79 & 0.07 & 284 & 0.8 & 0.08 & 0.08 \\
\hline
\end{tabular}

${ }^{*} P$-value indicates the level of significance; $F$ test was used. Level of significance was set $<0.05$ 
among males than females $(25.6 \%$ vs. $17.2 \%, P<0.001)$ (results not shown).

Table 3 shows the unadjusted and adjusted associations of the three outcome measures of overweight (BMI, WC and WHR) with early weight gain. Compared to gradual growth, rapid growth tended to increase the risk of overweight among young adults as measured by BMI, but the association was not statistically significant (adjusted OR = 1.13, 95 \% CI, 0.86-1.49) . A similar trend was observed in the WC categories (adjusted OR $=1.24,95 \% \mathrm{CI}, 0.92$ 1.67). The z-score of postnatal weight gain or the rate of postnatal growth did not have any impact on young adults' WHR. Adjusting for confounders did not attenuate these associations.

While slow growth reduced the risk of developing overweight/obesity (classified by BMI) in young adulthood (adjusted OR $=0.62,95 \% \mathrm{CI}, 0.45-0.84$ ), rapid growth substantially increased that risk compared to gradual growers (adjusted OR $=2.35,95 \% \mathrm{CI}, 1.82-$ 3.03) (Table 3). Rapid weight gain in the first five years of life increased the risk of becoming overweight more than twofold. A similar trend was observed for WC categories. When overweight and obesity was defined by $\mathrm{WC}$, the children who gained weight rapidly in their first five years of life had over a two-fold increased risk of developing overweight in young adulthood (adjusted $\mathrm{OR}=2.20,95 \% \mathrm{CI}, 1.65-2.95)$. Unlike BMI, slow growth was not strongly associated with WC status. Although rapid growth increased the risk of overweight status measured by WHR, the association was not significant (unadjusted OR $=1.25,95 \% \mathrm{CI}, 0.94-1.66$; adjusted OR $=1.16,95 \% \mathrm{CI}, 0.87-1.57)$ (Table 3 ).

\section{Discussion}

Using a large community-based cohort study, we found that the rate of weight gain in the first six months of life was not significantly associated with BMI, WC or WHR in young adults. When excess weight gain occurred in children over a more extended period of time (birth to 5 years), it increased their risk of presenting with a higher BMI and WC in young adulthood. Slow growth appeared to reduce the risk of developing overweight, but the association was only significant with BMI. Adult overweight status measured by WHR was not significantly influenced by early weight gain. All these associations were not explained by the potential confounding and mediating factors.

A stronger association between postnatal weight gain and a subsequent higher BMI can be found in childhood $[2,5,6,23-29]$ and adolescence [13, 30, 31]. Many studies that reported a strong positive association between rapid weight gain and obesity later in life measured exposure and outcome at closer time-points [5, 26-28, 32]. From the MUSP cohort, Mamun et al. [33] reported a positive association between postnatal weight gain $(1 \mathrm{~g} /$ day in the first six months of life) and overweight at 5 and 14 years of age. In a recent study, any significant association between weight gain during $0-1$ years or $1-2.5$ years and obesity in young adults was not found [14].. McCarthy et al. [15] conducted detailed analyses from anthropometric measures at 14 time-points from birth to 5 years and then at 25 years of age, and found a positive association between infant growth and BMI at 25 years. However, weight gain between 21 months and 5 years $(\beta=0.99, P<0.001)$ predicted a stronger association than between 0 and 5

Table 3 Association between early weight gain and young adults' BMI, WC and WHR categories in the MUSP cohort: logistic regression analysis

\begin{tabular}{|c|c|c|c|c|c|c|c|c|c|c|c|c|c|c|c|c|c|c|}
\hline \multirow[b]{4}{*}{ Z-score of postnatal weight gain } & \multicolumn{6}{|c|}{ BMl categories $^{\mathrm{a}}$} & \multicolumn{6}{|c|}{ WC categories $^{b}$} & \multicolumn{6}{|c|}{ WHR categories $^{c}$} \\
\hline & \multicolumn{3}{|c|}{ Unadjusted } & \multicolumn{3}{|c|}{ Adjusted } & \multicolumn{3}{|c|}{ Unadjusted } & \multicolumn{3}{|c|}{ Adjusted } & \multicolumn{3}{|c|}{ Unadjusted } & \multicolumn{3}{|c|}{ Adjusted } \\
\hline & \multirow{2}{*}{$\frac{\mathrm{OR}}{1.05}$} & \multicolumn{2}{|c|}{$95 \% \mathrm{Cl}$} & \multirow{2}{*}{$\frac{\mathrm{OR}}{1.06}$} & \multirow{2}{*}{\multicolumn{2}{|c|}{$\frac{95 \% \mathrm{Cl}}{0.97 \quad 1.16}$}} & \multirow{2}{*}{$\frac{\mathrm{OR}}{0.98}$} & \multicolumn{2}{|c|}{$95 \% \mathrm{Cl}$} & \multirow{2}{*}{$\frac{\mathrm{OR}}{1.03}$} & \multicolumn{2}{|c|}{$95 \% \mathrm{Cl}$} & \multirow{2}{*}{$\frac{\mathrm{OR}}{0.99}$} & \multicolumn{2}{|c|}{$95 \% \mathrm{Cl}$} & \multirow{2}{*}{$\frac{\mathrm{OR}}{0.93}$} & \multicolumn{2}{|c|}{$95 \% \mathrm{Cl}$} \\
\hline & & 0.97 & 1.13 & & & & & 0.91 & 1.06 & & 0.95 & 1.14 & & 0.89 & 1.06 & & 0.84 & 1.02 \\
\hline Rate of postnatal weight gain & \multicolumn{18}{|c|}{ Reference: Gradual ( $\geq-0.67$ to $\leq+0.67$ ) } \\
\hline Slow $(<-0.67$ SDS $)$ & 0.96 & 0.77 & 1.20 & 0.94 & 0.74 & 1.19 & 1.22 & 0.96 & 1.53 & 1.08 & 0.84 & 1.39 & 0.98 & 0.75 & 1.26 & 1.07 & 0.81 & 1.40 \\
\hline Rapid (> + 0.67 SDS) & 1.13 & 0.87 & 1.47 & 1.13 & 0.86 & 1.49 & 1.20 & 0.91 & 1.59 & 1.24 & 0.92 & 1.67 & 1.05 & 0.77 & 1.42 & 0.97 & 0.71 & 1.32 \\
\hline $\begin{array}{l}\text { Z-score of early childhood weight gain } \\
\text { (0-5 years) }\end{array}$ & 1.62 & 1.46 & 1.79 & 1.70 & 1.51 & 1.90 & 1.38 & 1.24 & 1.54 & 1.49 & 1.31 & 1.68 & 1.14 & 1.01 & 1.27 & 1.10 & 0.98 & 1.24 \\
\hline $\begin{array}{l}\text { Rate of early childhood weight gain } \\
(0-5 \text { years })\end{array}$ & \multicolumn{12}{|c|}{ Reference: Gradual $(\geq-0.67$ to $\leq+0.67)$} & & & & & & \\
\hline Slow $(<-0.67$ SDS $)$ & 0.69 & 0.51 & 0.92 & 0.62 & 0.45 & 0.84 & 0.89 & 0.63 & 1.24 & 0.78 & 0.55 & 1.11 & 0.75 & 0.52 & 1.07 & 0.75 & 0.52 & 1.08 \\
\hline Rapid (> + 0.67 SDS) & 2.31 & 1.83 & 2.93 & 2.35 & 1.82 & 3.03 & 1.94 & 1.49 & 2.54 & 2.20 & 1.65 & 2.95 & 1.25 & 0.94 & 1.66 & 1.16 & 0.87 & 1.57 \\
\hline \multicolumn{19}{|c|}{$\begin{array}{l}\text { Variables considered in the adjusted model: gender, gestation, } \\
\text { activity at } 14 \text { years, maternal education, maternal age at birth, } \\
\text { OR odds ratio, SDS standard deviation score, } C l \text { confidence inter } \\
\text { a Adjusted analysis: } 0-6 \text { months, } N=1768 ; 0-5 \text { years, } N=1601 \\
\text { bAdjusted analysis: } 0-6 \text { months, } N=1769 ; 0-5 \text { years, } N=1396 \\
\text { cAdjusted analysis: } 0-6 \text { months, } N=1768 ; 0-5 \text { years, } N=1395\end{array}$} \\
\hline
\end{tabular}


months $(\beta=0.43, P=0.02)$. Although the effect size of rapid postnatal growth from this current study was comparable to the findings of McCarthy et al. [15], it was not statistically significant (adjusted $\beta=0.45, \mathrm{SE}=$ $0.30, P=0.1$ ). Whitaker et al. [34] also reported that obesity before 3 years of age was weakly correlated with adult obesity. It is likely that many mediating factors in adolescence could have exerted an influence on the association and attenuated the effect at 21 years. However, our results are in contrast to some previous studies that had sample sizes $<700[3,4,13]$. In industrialised countries, overweight is believed to be associated with poor socioeconomic factors [35]. In the MUSP cohort, a higher percentage of mothers with low socio economic status were reported to drop out in the follow-ups [16], and this was also observed in the main analysis set. Therefore, this bias could have attenuated the effect size of the association between rapid early weight gain and overweight in young adulthood.

Nutrition and life-style factors during early childhood could have a greater impact on developing the overweight phenotype than that during postnatal period. In a recent randomised control trial, the effectiveness of early intervention on healthy food intake and physical activity among Australian infants was studied [36]. The authors reported that the intervention group had a significantly lower BMI at 2 years of age than the control group $\left(0.29 \mathrm{~kg} / \mathrm{m}^{2}, 95 \% \mathrm{CI},-0.55\right.$ to -0.02$)$. They found measurable differences between the groups in infants' vegetable consumption, food for reward and televisionviewing [36]. These results suggest that early modifiable infant factors contribute considerably towards the development of overweight and obesity among children.

WC and WHR are better measurements of abdominal obesity, and the fat mass index is also strongly correlated with WC [31] and in the present study, rapid weight gain during $0-6$ months increased young adults' WC, but the association was not significant. However this effect size is comparable with a previous study $(\mathrm{N}=248)$ where weight gain 0-6 months resulted in an increased WC at 17 years (adjusted $\beta=1.40, P<0.004$ ) [13]. Similar results were reported for the effects of rapid gain in the first three months of life in young adults [37]. It was not possible in this study to ascertain whether the observed increase in WC was due to higher symmetrical growth or abdominal obesity; however, the effects of early rapid weight gain were not substantially attenuated when adjusted for critical factors such as race, maternal prepregnancy BMI, physical activity and puberty. Although rapid growth at both time points measured in this study appeared to increase the risk of a higher WHR, it was not statistically significant. Similar findings were observed by McCarthy et al. [15] who found that weight gain at different intervals $(0-5$ months, $5-21$ months and
21 months -5 years) failed to predict any significant changes in WHR at 25 years of age. WHR is an indirect measure of metabolic disorders. As a result, it is also possible that young adulthood is still too early to differentially express the adverse effects of rapid growth through WHR although it could well be expressed in late young adulthood or mid-adulthood. Most studies reporting an association between postnatal weight gain and subsequent obesity have considered potential perinatal confounders but rarely childhood factors, which were considered in multivariate analysis. However, the validity of self-reported physical activity and television viewing may be suboptimum. Intake of fat food was measured through the frequency of fast food consumption by the family, and it may not be an accurate measure of fat intake by individuals.

Longer-term follow-up of the participants was one of the strength of the study. Measurements of weight and height by trained persons, such as those used in MUSP are considered to have a higher accuracy [35].

However, there are some limitations in the study as well. The MUSP cohort predominantly consists of a middle- to-lower socioeconomic families and attrition was considerably high [16]. However, our analysis and previous analyses samples from MUSP cohort show a smaller impact on findings due to attrition [38]. Postnatal weight was reported by mothers during the 6-month follow-up, thus limiting the validity of the measurement. It was also not possible to define the postnatal period with regard to weight gain as the mothers were contacted 4-9 months post-delivery (mean 6.07 months). These systematic errors could have biased the association and the ability to predict the critical postnatal period. There were concerns about the accuracy of the WC measurements during the 21-year follow-up of the study [19]. As the analyses employed here compared the mean values among groups and not the absolute values, it is unlikely that the observed association was substantially affected.

\section{Conclusions}

The findings of this prospective cohort study confirm that an increased rate of weight gain in the first five years of life is associated with a greater risk of overweight and obesity, as defined by both BMI and WC, in young adulthood. In contrast, slow early childhood growth was associated with lower young adulthood BMI levels. Waist-to-hip ratios at 21 years did not predict the adverse effects of early weight gain which could become more evident in middle age. The findings of this study suggest that slow or optimal growth in early life, especially in first 5 years of life, may protect or reduce the young adult overweight and obesity. 


\section{Competing interests}

The authors declare that they have no competing interests.

\section{Authors' contributions}

RS and AM conceived the idea. RS carried out the analyses and drafted the manuscript. AM and GW supervised the statistical analyses and critically reviewed the manuscript. JN and MO designed the overall study and critically edited the manuscript. All authors read and approved the final manuscript.

\section{Acknowledgements}

The authors thank the National Health and Medical Research Council of Australia (NHMRC) for funding this project. AAM was supported by a NHMRC Career Development Awards for this work. The views expressed in this paper are those of authors and not necessarily those of any funding body, and no funding body influenced how the data were analysed and presented. The authors are thankful of all the participants in this study, the MUSP team, the data manager at the University of Queensland, the Mater Misericordiae Hospital and the School of Social Science and Population Health for their support. They acknowledge of the contribution of the members of the MUSP 21-year follow-up team.

\section{Author details}

${ }^{1}$ School of Population Health, The University of Queensland, Brisbane, Australia. ${ }^{2}$ Eskitis Institute, Griffith University, Brisbane, Australia. ${ }^{3}$ Mater Children's Hospital, Brisbane, and The University of Queensland, Brisbane, Australia. ${ }^{4}$ School of Social Science, The University of Queensland, Brisbane, Australia.

Received: 29 May 2015 Accepted: 26 June 2015

\section{Published online: 08 August 2015}

\section{References}

1. WHO. Obesity and overweight. World Health Organisation. Fact Sheet No 311201104 Aug 2013. Available from: http://www.who.int/mediacentre/ factsheets/fs311/en/index.html.

2. Ong KKL, Ahmed ML, Emmett PM, Preece MA, Dunger DB. Association between postnatal catch-up growth and obesity in childhood: prospective cohort study. Br Med J. 2000;320(7240):967-71.

3. Stettler N, Stallings VA, Troxel AB, Zhao J, Schinnar R, Nelson SE, et al. Weight gain in the first week of life and overweight in adulthood-A cohort study of European American subjects fed infant formula. Circulation. 2005;111(15):1897-903.

4. Stettler N, Kumanyika SK, Katz SH, Zemel BS, Stallings VA. Rapid weight gain during infancy and obesity in young adulthood in a cohort of African Americans. Am J Clin Nutr. 2003;77:1374-8.

5. Stettler N, Zemel BS, Kumanyika S, Stallings VA. Infant weight gain and childhood overweight status in a multicenter, cohort study. Pediatrics. 2002;109:194-9.

6. Tanaka T, Matsuzaki A, Kuromaru R, Kinukawa N, Nose Y, Matsumoto T, et al. Association between birthweight and body mass index at 3 years of age. Pediatr Int. 2001;43(6):641-6.

7. Baird J, Fisher D, Lucas P, Kleijnen J, Roberts H, Law C. Being big or growing fast: systematic review of size and growth in infancy and later obesity. BMJ. 2005;331:929.

8. Druet C, Stettler N, Sharp S, Simmons RK, Cooper C, Davey Smith G, et al. Prediction of childhood obesity by infancy weight gain: an individual-level meta-analysis. Paediatr Perinat Epidemiol. 2012;26(1):19-26.

9. Monteiro PO, Victora CG. Rapid growth in infancy and childhood and obesity in later life[mdash]a systematic review. Obes Rev. 2005;6:143-54.

10. Ong K, Loos R. Rapid infancy weight gain and subsequent obesity: systematic reviews and hopeful suggestions. Acta Paediatr. 2006;95:904-8.

11. Monasta L, Batty GD, Cattaneo A, Lutje V, Ronfani L, Van Lenthe FJ, et al. Early-life determinants of overweight and obesity: a review of systematic reviews. Obes Rev. 2010;11(10):695-708.

12. Demerath EW, Reed D, Choh AC, Soloway L, Lee M, Czerwinski SA, et al. Rapid Postnatal Weight Gain and Visceral Adiposity in Adulthood: The Fels Longitudinal Study. Obesity. 2009;17(11):2060-6.

13. Ekelund U, Ong K, Linné Y, Neovius M, Brage S, Dunger DB, et al. Upward weight percentile crossing in infancy and early childhood independently predicts fat mass in young adults: the Stockholm Weight Development Study (SWEDES). Am J Clin Nutr. 2006;83(2):324-30.

14. Fåhraeus $C$, Wendt L-K, Nilsson M, Isaksson H, Alm A, Andersson-Gäre B. Overweight and obesity in twenty-year-old Swedes in relation to birthweight and weight development during childhood. Acta Paediatr. 2012;101(6):637-42.

15. McCarthy A, Hughes R, Tilling K, Davies D, Davey Smith G, Ben-Shlomo Y. Birth weight; postnatal, infant, and childhood growth; and obesity in young adulthood: evidence from the Barry Caerphilly Growth Study. Am J Clin Nutr. 2007;86(4):907-13.

16. Najman J, Bor W, O'Callaghan M, Williams G, Aird R, Shuttlewood G. Cohort Profile: The Mater-University of Queensland Study of Pregnancy (MUSP). Int J Epidemiol. 2005;34(5):992-7.

17. Keeping JD, Najman JM, Morrison J, Western JS, Andersen MJ, Williams GM A prospective longitudinal study of social, psychological and obstetric factors in pregnancy: response rates and demographic characteristics of the 8556 respondents. BJOG. 1989;96(3):289-97.

18. WHO. Obesity: preventing and managing the global epidemic. Report of a WHO consultation. World Health Organisation Tech Rep Ser 2000; 894: 1-253. 2000 22/03/2012. Available from: http://whqlibdoc.who.int/trs/ who_trs_894.pdf.

19. Liddle K, O'Callaghan M, Mamun A, Najman J, Williams G. Comparison of body mass index and triceps skinfold at 5 years and young adult body mass index, waist circumference and blood pressure. J Paediatr Child Health. 2012;48(5):424-9.

20. Tanner J. Growth at Adolescence: Blackwell: Oxford. 1962.

21. Mamun A, Hayatbakhsh M, O'Callaghan M, Williams G, Najman J. Early overweight and pubertal maturationFpathways of association with young adults' overweight: a longitudinal study. Int J Obes. 2009;33:14-20.

22. Magarey AM, Daniels LA, Boulton TJ. Prevalence of overweight and obesity in Australian children and adolescents: reassessment of 1985 and 1995 data against new standard international definitions. Med J Aust. 2001;174:561-4.

23. Stettler $N$, Bovet $P$, Shamlaye $H$, Zemel BS, Stallings VA, Paccaud F. Prevalence and risk factors for overweight and obesity in children from Seychelles, a country in rapid transition: the importance of early growth. Int J Obes. 2002;26(2):214-9.

24. Karaolis-Danckert N, Buyken AE, Bolzenius K, de Perim Faria C, Lentze MJ, Kroke A. Rapid growth among term children whose birth weight was appropriate for gestational age has a longer lasting effect on body fat percentage than on body mass index. Am J Clin Nutr. 2006;84(6):1449-55.

25. Kinra S, Baumer JH, Davey Smith G. Early growth and childhood obesity: a historical cohort study. Arch Dis Child. 2005;90(11):1122-7.

26. Taveras EM, Rifas-Shiman SL, Sherry B, Oken E, Haines J, Kleinman K, et al. Crossing Growth Percentiles in Infancy and Risk of Obesity in Childhood. Arch Pediatr Adolesc Med. 2011;165(11):993-8.

27. Taveras EM, Rifas-Shiman SL, Belfort MB, Kleinman KP, Oken E, Gillman MW. Weight Status in the First 6 Months of Life and Obesity at 3 Years of Age. Pediatrics. 2009;123(4):1177-83.

28. Terry MB, Wei Y, Esserman D, McKeague IW, Susser E. Pre- and postnatal determinants of childhood body size: cohort and sibling analyses. J Dev Origins Health Dis. 2011;2(02):99-111.

29. Durmuş B, Kruithof CJ, Gillman MH, Willemsen SP, Hofman A, Raat H, et al Parental smoking during pregnancy, early growth, and risk of obesity in preschool children: the Generation R Study. Am J Clin Nutr. 2011;94(1):164-71.

30. Monteiro POA, Victora CG, Barros FC, Monteiro LMA. Birth size, early childhood growth, and adolescent obesity in a Brazilian birth cohort. Int J Obes. 2003;27(10):1274-82.

31. Eriksson M, Tynelius P, Rasmussen F. Associations of birthweight and infant growth with body composition at age 15-the COMPASS study. Paediatr Perinat Epidemiol. 2008;22(4):379-88.

32. Parsons TJ, Power C, Manor O. Fetal and early life growth and body mass index from birth to early adulthood in 1958 British cohort: longitudinal study. BMJ. 2001;323(7325):1331-5.

33. Mamun AA, Lawlor DA, O'Callaghan MJ, Williams GM, Najman JM. Family and early life factors associated with changes in overweight status between ages 5 and 14 years: findings from the Mater University Study of Pregnancy and its outcomes. Int J Obes (Lond). 2005;29:475-82.

34. Whitaker RC, Wright JA, Pepe MS, Seidel KD, Dietz WH. Predicting obesity in young adulthood from childhood and parental obesity. N Engl J Med. 1997;337:869-73. 
35. Lobstein T, Baur L, Uauy R. Obesity in children and young people: a crisis in public health. Obesity reivews. 2004;5 Suppl 1:4-85.

36. Wen L, Baur L, Simpson J, Rissel C, Wardle K, Flood V. Effectiveness of home based early intervention on children's BMl at age 2: randomised controlled trial. BMJ. 2012;344, e3732.

37. Leunissen RWJ, Kerkhof GF, Stijnen T, Hokken-Koelega A. Timing and Tempo of First-Year Rapid Growth in Relation to Cardiovascular and Metabolic Risk Profile in Early Adulthood. JAMA. 2009;301(21):2234-42.

38. Mamun AA, O'Callaghan MJ, Williams GM, Najman JM. Change in maternal body mass index is associated with offspring body mass index: a 21-year prospective study. Eur J Nutr. 2013;52(6):1597-606.

\section{Submit your next manuscript to BioMed Central} and take full advantage of:

- Convenient online submission

- Thorough peer review

- No space constraints or color figure charges

- Immediate publication on acceptance

- Inclusion in PubMed, CAS, Scopus and Google Scholar

- Research which is freely available for redistribution 